\title{
Instructional principles used to teach critical comprehension skills to a Grade 4 learner
}

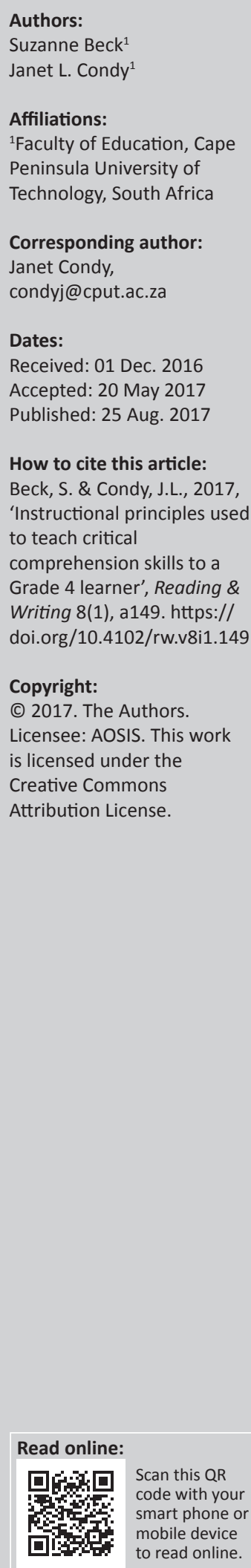

The current approach to reading comprehension instruction is not producing the desired outcomes. Provincial, national and international tests indicate that more than half of South African learners cannot read, understand and answer basic comprehension questions. This research project was informed by Vygotsky's socio-cultural theory. A case study was conducted with a ten-year old Grade 4 boy who experienced difficulty with understanding comprehension questions. A six-week intervention was designed to improve his comprehension abilities and to identify instructional principles that were appropriate for him. Interviews and observations were conducted and inductively analysed. Findings showed that the learner was well equipped to retrieve explicitly stated information but struggled with higher-order level questions such as drawing inferences or evaluating content. Certain instructional practices were more favourable than others when teaching reading strategies.

\section{Introduction}

South Africa participates in many provincial and national assessments for both Literacy and Numeracy, for example: provincially, the Western Cape Education Department (WCED) conducts annual Systemic tests - Annual National Assessments (ANA) were conducted nationally between 2011 and 2014 and internationally, the Progress in International Reading Literacy Study (PIRLS) is conducted every five years. In the National Department of Basic Education's Report on the Annual National Assessment of 2014, Minister Motsheka stated that:

\footnotetext{
$\ldots$ it is hoped that effective testing will afford learners the opportunity to demonstrate relevant skills and understanding and also assist the education system with diagnosing learner shortcomings... can provide valuable feedback to schools, teachers, learners and parents. (National Department of Basic Education [NDoBE] 2014:1)
}

Not only are these test results supposed to provide necessary diagnostic information to the schooling community but to lecturers and researchers in tertiary institutions where one of the authors of this research was a post-graduate student. This particular case study was conducted in her Grade 4 class in an urban quintile 5 school. The Department of Basic Education classifies schools in five quintiles, poorer and no-fee schools make up quintiles 1 and 2 while quintile 5 schools are considered the 'richest'. This classification is based on the economic status of the learners who attend the school (Gower 2008:15). The amount of subsidisation that the school receives from the Education Department is directly proportioned according to the school's quintile ranking. We begin by analysing the three assessments in order to answer the research question 'What instructional principles are used to teach a Grade 4 learner more critical comprehension skills?'

In 2015, the WCED published their results of the Systemic tests in Language for Grade 3 and provided a breakdown of the skill percentage passes. As this study's focus is on 'comprehension', only the results of the related two sub-skills are included, which include: Reading and Viewing, and Thinking and Reasoning. We have selected to highlight only the quintile 5 WCED Systemic results for Grade 3.

As can be seen by the results described in Table 1, the WCED's Systemic results for quintile 5, Grade 3 Language results indicate that just over half the students evaluated exhibited a basic understanding of the Grade 3 Literary skills. It is pleasing to note that the marks have improved slightly from 2013 to 2015 . However, when looking more closely at the comprehension subskills' results of Reading and Viewing, and Thinking and Reasoning, it appears that less than half of the Grade 3 learners understood these types of questions. 
TABLE 1: Western Cape Education Department's 2015 Systemic test percentage of learners who passed language in Grade 3 and a further description of the results of the two comprehension sub-skills.

\begin{tabular}{lllll}
\hline Years & $\mathbf{2 0 1 1}$ & $\mathbf{2 0 1 2}$ & $\mathbf{2 0 1 3}$ & $\mathbf{2 0 1 4}$ \\
\hline Grade 3 & 53.2 & 61.0 & 58.4 & $\mathbf{2 0 1 5}$ \\
Reading and viewing & 26.0 & 41.7 & 37.0 & 65.4 \\
Thinking and reasoning & 44.4 & 40.7 & 37.2 & 43.2 \\
\hline
\end{tabular}

44.4

40.7

37.2

42.4

Source: Data taken from Western Cape Education Department, 2015, WCED Systemic tests for Grades 3, 6 and 9: 2015 results, [Power point presentation] Research Department, Cape Town

TABLE 2: The 2014 Annual National Assessments results for Grade 3 of learners who passed.

\begin{tabular}{llll}
\hline Grade & $\mathbf{2 0 1 2}$ & $\mathbf{2 0 1 3}$ & $\mathbf{2 0 1 4}$ \\
\hline Grade 3 & $52 \%$ & $51 \%$ & $56 \%$ \\
\hline
\end{tabular}

The 2014 Annual National Assessments (ANA) were conducted in Grades 3,6 and 9. The results are indicated in Table 2 and again the researchers focussed only on the Grade 3 Literacy results of the learners who passed. Motsheka (NDoBE 2014:1) claims:

Many learners in both Home Language and First Additional Language struggle to respond to questions that:

1. Require the use of their own words. Therefore, summarising a text using own words, becomes extremely difficult.

2. Learners are unable to interpret a sentence or give an opinion when required.

Similarly, when one examines the international results from the PIRLS 2011 Grade 5 comprehension tests, more than half of South African learners only reached the Low International benchmark as can be seen in Table 3 (Howie et al. 2012).

The results of the PIRLS indicate that the majority of South African learners are unable to draw straightforward inferences and integrate ideas (Combrinck, Van Staden \& Roux 2014). According to Mokhtari and Reichard (2002), such unskilled readers regard reading as a decoding process rather than a meaning-making process and often do not realise that they do not understand what they have read.

What is consistently reinforced about South African learners from the results of these three tests, according to Spaull et al. (2016), is:
.... less than half of all learners learn to read for meaning in this critical period. These weak foundations provided in Grades 1 - 3 constitute one of the major factors leading to poor learning outcomes in later grade. (p. 4)

This research project was conducted in an English Grade 4 classroom in a public, mainstream primary school situated in a low to middle socio-economic urban area. This quintile 5 school had a teacher-to-pupil ratio of 1:38 with annual school fees of R1 800. After working in this grade for two years, the researcher identified that many of her learners performed below average in reading comprehension. This restricted her learners during Home Language lessons and assessments as well as constrained participation in lessons and assessments of other subjects. Most learners were able to answer questions about explicitly stated information but were unable to draw inferences, make connections to the text or evaluate content.
Many of her learners did not understand that the aim of a comprehension exercise was the acquisition of information. In formal assessment tasks, where learners were given a text and a set of questions, they appeared to read the text once, without stopping to process and question information. They would then answer questions without further reference to the text. These learners did not seem to be equipped with the skills and strategies to gain complete comprehension and process written information: As a result of this, many learners were underachieving.

\section{Literature review}

This section discusses: definitions of literacy, comprehensions in terms of skills, instructional practices such as explicit teaching, guided reading, and whole and small group reading.

Two definitions of literacy are examined. The current Foundation and Intermediate Phase curriculum in South Africa is the Curriculum Assessment and Policy Statement (CAPS) document (NDoBE 2011) which was implemented in 2011. This document defines literacy skills in the Foundation Phase (Grades R-3) as: listening and speaking, reading and phonics, and writing and handwriting, while thinking and reasoning, and language structure and use are underlying skills. In the Intermediate Phase (Grades $4-6$ ), listening, speaking and language usage skills are further developed and refined but with an emphasis on reading and writing skills. The reading skills include developing proficiency in reading a wide range of genres to reflect on the purpose, audience and context of texts and to develop learners to become more critical and creative thinkers. The CAPS (NDoBE 2011) document states that 'comprehension' should be taught but does not prescribe how it should be taught: As a result, many teachers opt for an implicit approach when teaching comprehension, meaning that they do not teach reading comprehension and its related strategies in isolation or in a clear, unambiguous manner but rather assume that learners will improve their comprehension ability by simply completing comprehension exercises without any instructional input.

According to international authors Mullis et al. (2009), the authors of the PIRLS 2011 assessments, they define comprehension as:

\footnotetext{
... reading literacy is defined as the ability to understand and use those written language forms required by society and/or valued by the individual. Young readers can construct meaning from a variety of texts. They read to learn, to participate in communities of readers in school and everyday life, and for enjoyment. (p. 11)
} 
TABLE 3: Progress in International Reading Literacy Study 2011 international benchmarks of reading achievement.

\begin{tabular}{|c|c|c|c|c|c|}
\hline $\begin{array}{l}\text { Benchmarks of reading } \\
\text { achievement }\end{array}$ & $\begin{array}{l}\text { Did not reach - Did not } \\
\text { reach any benchmark }\end{array}$ & $\begin{array}{l}\text { Reached - Low International } \\
\text { benchmark: Focus on } \\
\text { retrieving explicitly } \\
\text { stated information }\end{array}$ & $\begin{array}{l}\text { Reached - Intermediate } \\
\text { International benchmark: } \\
\text { Make straightforward } \\
\text { inferences }\end{array}$ & $\begin{array}{l}\text { Reached - High International } \\
\text { benchmark: Interpret and } \\
\text { integrate ideas and } \\
\text { information }\end{array}$ & $\begin{array}{l}\text { Reached - Advanced } \\
\text { International benchmark: } \\
\text { Evaluate and examine } \\
\text { content, language and } \\
\text { textual elements }\end{array}$ \\
\hline South Africa Grade 5 & 43 & 57 & 34 & 14 & 4 \\
\hline
\end{tabular}

Source: Data taken from Van Staden, S., 2012, PIRLS overall results [Power point presentation], Centre for Evaluation and Assessment, University of Pretoria, Pretoria

In South Africa, Grade 4, the start of the Intermediate Phase, is frequently characterised by learners who face comprehension difficulties (McNamara, Ozuru \& Floyd 2011) as they try to 'understand and use the written language forms required by society' (Mullis et al. 2009). Learners move from 'learning to read' in the Foundation Phase to 'reading to learn' in the Intermediate Phase (Sanacore \& Palumbo 2009) where the emphasis of comprehension shifts to 'constructing meaning from a variety of texts ... and for enjoyment' (Mullis et al. 2009). All learning becomes dependent on the learner's ability to understand the written word, whereas the focus was previously on the ability to pronounce the written word. If learners lack the ability to comprehend or use comprehension strategies effectively by Grade 3, they will fall behind their peers and find it difficult to catch up (Flynt \& Cooter 2005; Geary 2006; Prado \& Plourde 2011).

Comprehension requires the reader to metacognitively combine the meanings of individual words into a coherent sentence, and then assimilate multiple sentences to create an overall understanding of the text (McNamara et al. 2011). If children encounter difficulties with these two steps and do not have a set of strategies to assist them in understanding the text on their own, they will lose interest (Prado \& Plourde 2011). Reading strategies are associated with decoding texts, understanding words and constructing meaning from texts (Combrinck et al. 2014). There are multiple reading strategies that can assist children with reading comprehension. Duke and Block (2012) emphasise predicting, questioning, visualising, drawing inferences and summarising as effective metacognitive strategies. Taylor et al. (2000) include the importance of small group instruction and the use of higherlevel questioning in their raft of strategies. Creating mental pictures of what is being read and using background knowledge to make connections are two more strategies to help readers develop their comprehension skills (Prado \& Plourde 2011).

Instructional practices when working with comprehension support explicit teaching as opposed to implicit teaching of reading (Prado \& Plourde 2011). Reading comprehension can be improved when these reading strategies are taught (Klapwijk 2012; Oyetunji 2013). According to Cambourne (2004:33), 'explicit teaching refers to the practice of deliberately demonstrating and bringing learners' conscious awareness to those invisible processes, understandings, knowledge and skills they need to acquire if they are to become effective readers'. Explicit teaching includes teachers providing reasons and purposes for the choice of texts to work with and reasons for activities conducted with texts. Prado and Plourde (2011) believe that the goal of explicit reading strategy instruction should be to improve the reader's comprehension skills. Equipping learners with reading strategies enables them to read independently, that is, when the teacher is not present. Teachers who explicitly teach effective literacy behaviours and who role model critical reading and writing skills help learners who come from homes where this is not provided.

Implicit teaching refers to the practice of deliberately leaving it to the learners to discover and work out these skills for themselves. South African teachers seldom teach reading strategies explicitly either because they believe that it is too time-consuming or because they feel inadequately trained to do so (Klapwijk 2012). Teachers who attempt to transfer reading strategies implicitly are actually testing rather than teaching these strategies (Oyetunji 2013).

Flynt and Cooter (2005) as well as Prado and Plourde (2011) believe that children need to see reading strategies modelled and be led through guided practice before they are given time to practise independently. Combrinck et al. (2014) state that practising reading strategies alone may not be enough for the reader. Metacognitive instruction about how and why we use strategies and guided practices may be more beneficial to the child's progress. Moss and Young (2010:95) state that '... guided reading enables students to try certain skills and strategies with your support'. The teacher normally selects the texts, offers guidance (Cohen 2008) before the reading begins and monitors the students reading performance. Moss and Young (2010:95) suggest that when planning a guided lesson, the teacher must take into consideration the purpose of the strategy to be taught, choose a text appropriate to the level of the learner and plan how the text, reading and discussion will be introduced. During the lessons, the teacher needs to monitor and observe the learners reading and involve the learner in discussions on the text. To reflect on the lesson, the teacher needs to reflect on whether the purpose of the lesson was achieved, how the learner engaged with the text and the strategies used. Duke and Block (2012) concur with the above researchers and extend their ideas by emphasising that it is essential for teachers to create a motivating environment for children. Teachers can show learners the benefits of reading by offering them choices in the topics and texts that they read. Cambourne (2004:27) states that '... how we teach is just as important as what we teach'.

Taylor et al. (2000) highlight the importance of small group instruction when teaching reading and reading strategies. Small group instruction is beneficial, specifically to learners who experience learning difficulties: It allows instruction to be tailored to the learner's specific need(s). Donald, Lazarus 
and Lolwana (2007:86) argue that through '... speaking, reading, writing and interacting within a particular discourse, people internalise that way of thinking.' As teachers and children interact in small groups with comprehension exercises, the form of language that is used shapes the way they begin to think, and shapes their construction of knowledge.

Hence, this small research project, underpinned by Vygotsky's socio-cultural theory, aimed to investigate instructional principles that were necessary to teach a Grade 4 boy more critical comprehension abilities.

\section{Theoretical Framework}

Lucy (1988) cites Vygotsky's theory of socio-cultural development and states that individual human development is a social process in which culture is the main determining factor. Social interactions, which take place in the child's immediate and external environment, play a significant role in the child's development and allow children the opportunity to acquire knowledge and develop processes. To benefit optimally from such interactions and problemsolving experiences, a learner should be actively involved in the process.

Donald et al. (2007:86) state that Vygotsky '... has helped us understand that the development of cognition in children is related to the social construction of knowledge... passing on values, information and ways of understanding through social interactions.' Santrock (2011:50) explains that 'the importance of social influences, especially instruction, on children's cognitive development is reflected in Vygotsky's concept of the Zone of Proximal Development (ZPD)'. The ZPD differentiates the gap between what a child can do on their own without help and what a child can do with adult guidance or more capable peers. In assuming responsibility for early tuition, the adult instructor scaffolds the process through language: The adult uses speech to guide the child. The responsibility is transferred to the child when they can use their own speech to interact with others, for 'self-talk' purposes and eventually as internal speech to direct their behaviour (Lucy 1988). The level of achievement of a child and the level of potential achievement are clearly distinguished by Vygotsky (Bruner 1997:131). It is the 'teachers and more competent peers who direct student's social and cultural experiences' (Bruner 1997 cited in Wertsch 1990:90).

'Scaffolding' is when learners begin to internalise the new learning of the lesson, and assistance is gradually withdrawn. Adults, or more knowledgeable others, help learners to answer difficult questions or to solve problems by them asking leading questions (Vygotsky 1978 cited in Wittmer, Petersen \& Puckett 2013). The purpose of scaffolding is to help students acquire knowledge and skills they would not have learned on their own. As the students demonstrate mastery of the content, the learning aids are faded and removed. Over the course of a teaching session, a more skilled person - a teacher or advanced peer adjusts the amount of guidance to fit the child's current performance. When the student is learning a new task, a skilled person may use direct instruction. As the student's competence increases, less guidance is given. Scaffolding is often used to '... help students attain the upper limits of their ZPD' (Horowitz et al. 2005:105).

\section{Intervention programme}

The focus of the six-week intervention programme was to equip the Grade 4 learner with reading strategies which would help improve his critical thinking abilities when working with comprehension exercises. The pre-test comprehension passage, taken from the pre-PIRLs tests was called 'Two Giant Dinosaurs' and covered three levels of questioning, namely focussing on and retrieving explicitly stated information (low international benchmark), making straightforward inferences (intermediate international benchmark), and examining and evaluating content, language and textual elements (advanced international benchmark). This passage did not contain any interpreting and integrating ideas (high international benchmark).

The intervention programme took place during the regular intervention class, a weekly language support class for learners who are at-risk of not progressing to the next grade as a result of not meeting the required standard of achievement in English (50\%). This group lesson was held for an hour a week and from the third week an individual half-hour session was included for the learner on which this case study is based. One aspect of effective reading strategy instruction is small group instructional practice (Taylor et al. 2000) which allows for more individual attention and focus.

Throughout the intervention programme, each lesson started with the teacher explicitly stating the purpose of the lesson (Moss \& Young 2010) and which strategy would be covered during the lesson. An essential component of reading strategy instruction is the concept of explicit teaching (Cambourne 2004). The researcher was mindful of Vygotsky's sociocultural theory which suggests that individual human development is a social process: In order for learners to develop optimally, they must be involved actively in the process (Lucy 1988).

Hence, the text was read jointly by the teacher and the learners. The teacher paused along the way to model various reading strategies with the main focus being on the strategy for the day (Cohen 2008). Once finished with the text, the teacher modelled the activity linked to the strategy using the 'Think-Aloud' process. According to McLaughlin (2006:223), the Think-Aloud process provides a '...model for active thinking during the reading process' when teaching reading strategies such as: 'previewing, visualizing, monitoring, selfquestioning, making connections, knowing how words work, summarising and evaluating'. The guided practice began, either with the learners re-reading the same text or reading a different text. The learners were encouraged to 'think-aloud' and ask questions while reading and completing the respective activity. The teacher supported the reading and 
activity process by scaffolding within the ZPD, recognising when to gradually withdraw and allow the learners to '... internalize the new learning' and to demonstrate mastery of the content (Vygotsky 1978 cited in Wittmer et al. 2013).

The objective for each reading strategy was to move from teacher-directed activities (direct explanation and modelling) to shared responsibility activities (guided practice and application) and eventually for the learner to achieve independence when working with the strategies (McLaughlin 2006).

To support the emotional development of the learner, a behaviour modification chart was introduced. The aim of this chart was to encourage the learner to identify areas in which he thought he had done well during the lesson and for him to develop a more positive self-esteem.

\section{Method}

An interpretative case study was conducted using a sixweek intervention programme to assist a Grade 4 boy's understanding of reading strategies to improve his comprehension abilities and to identify which instructional practices the learner best responded to. Henning, Van Rensburg and Smit (2007:20) describes interpretivist research as looking for frames that shape meaning within social contexts. A mixed method research design was used in this study. At the beginning of the intervention programme, a pre-test was conducted to diagnostically identify the comprehension skills, strengths and challenges of the learner. After the six-week intervention programme the same test was given as a post-test. These results are discussed in the findings section.

The 10-year-old Grade 4, male learner was purposively selected as the sample on the basis that he experienced comprehension difficulties in making straightforward inferences and examining and evaluating content, language and textual elements. He was already attending the intervention classes offered by the teacher. The learner's Grade 3 teacher was interviewed because she had 'comprehensive knowledge' (Cohen Manion \& Morrison 2007) about this learner and had tried to address his specific comprehension difficulties the previous year. The researcher was able to gain a deeper understanding of how his poor comprehension skills affected his academic performance in the previous year, as well as the role that reading strategies played in his comprehension.

Multiple data collection methods were used in this mixed methods research project. Cohen et al. (2007) state that there are multiple views of reality and it is imperative that a variety of perspectives, voices and views be taken into account when collecting data. A semi-structured interview was conducted with the learner's Grade 3 teacher during August 2015. This type of interview was selected in order to allow the interviewer and respondent 'freedom and flexibility' (Cohen et al. 2007:355). These interviews gave the researcher an opportunity to enter into another person's perspective and return to events and experiences in the past that she was unable to replicate (Merriam 2009). The researcher asked the Grade 3 teacher about her understanding of the CAPS document in relation to comprehension skills, how she went about teaching comprehension skills in her class and whether she utilised different reading strategies. The teacher was further asked questions about this specific learner's reading and comprehension skills as well as her intervention programme she had used the previous year. Open-ended questions allowed the researcher to probe for in-depth answers as well as observe 'non-verbal reactions' (Kumar 2011:150).

Observations were used as a 'purposeful, systematic and selective way of watching and listening' to the learner (Kumar 2011:140). An observation schedule was used in order to gain first-hand experience of what difficulties the learner experienced when faced with a comprehension exercise and what, if any, reading strategies he accessed. The focus of the observations was on the learner's level of participation in the lesson and how he engaged with the teacher, group, texts and activities. His behaviour was observed to identify when and how the researcher needed to mediate. Observations took place during school hours when the learner was given a task which involved comprehension, as well as during the intervention classes after school hours. The learner was observed individually and in a group setting.

Merriam (2009) describes data analysis as a meaning-making process of data. The goal of data analysis is to uncover emerging themes, patterns and understandings (Patton 2002). Data were inductively analysed by transcribing the interviews verbatim and evaluating the observations. The collected data, along with the results of the pre-test and posttest, were compared in order to identify common themes that were relevant to the study. Once these themes were identified, they were coded: Each theme was given an abbreviation. The researcher was then able to 'quantify the main themes in order to provide their prevalence, and thus significance' (Kumar 2011:277).

Validity is seldom easy to establish (Cohen et al. 2007). In order to minimise bias, the researcher took the findings to the participants for confirmation and approval. The interview participants were able to tell the researcher whether the findings '... reflected their opinions and feelings accurately' (Kumar 2011:185). By using multiple data collection methods (weekly observations and two interviews), the researcher was able to identify common themes and achieve triangulation (Cohen et al. 2007).

In order to improve the trustworthiness of this research project, it was conducted in an 'ethical manner' (Merriam 2009). Written permission from the Western Cape Education Department, Cape Peninsula University of Technology, the school principal, the learner's past Grade 3 teacher and the learner's parent was obtained. The nature of the study and the 
intentions of the researcher were explained to all participants (Leedy \& Ormond 2005). To ensure the confidentiality of the participants, their responses were kept anonymous.

\section{Findings and discussion}

The purpose of this case study research aimed to investigate instructional principles that were necessary to teach a Grade 4 boy critical comprehension abilities. After inductively analysing the observations, two interview transcripts as well as the reading comprehension pre- and post-tests, the following two themes became evident:

- level of questioning

- reading strategy instructional practices.

\section{Level of questioning}

Table 4 provides data on the informational pre-and posttest comprehension results. The pre-test results indicate that the learner was able to deal with questions which required retrieval of explicitly stated information (e.g. What did Diplodocus eat?) but was unable to draw straightforward inferences (e.g. Why did T. Rex need to have such large jaws?) and experienced difficulty when examining and evaluating content, language and textual elements (e.g. How do the pictures of the T. Rex and Diplodocus help you learn about these two dinosaurs?). It was interesting to note the drop in scores for questions requiring the retrieval of explicitly stated information from pre-test to post-test, while the other more critical comprehension skills improved. The drop in scores for the retrieval of explicitly stated information may be explained by the researcher not focussing on these questions as the learner achieved $100 \%$ in the pre-test.

During the interview with the learner's Grade 3 teacher, she said the following about the types of activities she used when teaching reading comprehension:

We always discuss the 'who, what, where, when and how' questions when we read a text... [Teacher, female, Grade 3, 56]

During the intervention programme, the researcher observed that the learner was eager to participate and was verbally responsive to questions that required recall of explicitly stated information but that his enthusiasm dwindled and he 'appeared uninterested' when more critical questions were posed. It was evident that the learner had worked with explicitly stated information regularly and that he had had sufficient practice in this area. His ability in the other areas of reading comprehension such as, making straightforward inferences and examining and evaluating content, language and textual elements,

TABLE 4: Results of the pre-and post-test comprehension results.

\begin{tabular}{lcc}
\hline Question type & Pre-test \% & Post-test \% \\
\hline Focus on and retrieve explicitly stated information & 100 & 66 \\
Make straightforward inferences & 0 & 66 \\
$\begin{array}{l}\text { Examine and evaluate content, language and } \\
\text { textual elements }\end{array}$ & 25 & 50 \\
\hline
\end{tabular}

was not well developed. Exposure to, and practice of, higher order questions were not sufficient to enable him to answer these types of questions. He needed a set of strategies: modelling and guiding metacognition were used to do this (Combrinck et al. 2014).

\section{Reading strategy instructional practices}

Throughout the data collection process, it became evident that specific instructional practices were better suited than others for the teaching of reading strategies for this Grade 4 boy.

One of the earliest observations the researcher made was the way in which the learner responded during small group instruction in comparison to the classroom environment. He 'participated actively' during small group instruction but he appeared uninterested and disengaged in the classroom environment. The researcher noted the following in her observations regarding the learner's attitude to the lesson when it took place in a small group:

He appeared to be engaged with and interested in the lesson. [The researcher, female, Grade 4 teacher, 23]

The learner appeared comfortable, 'less anxious' and was more willing to take risks when working in a small group. This relaxation and cooperation were evident when he volunteered to answer a question even when he was unsure whether he had the 'correct' answer or not.

Another observation made by the researcher regarding favourable instructional practices was the use of 'explicit instruction' (Cambourne 2004:33). Initially, the researcher observed that when working on a comprehension exercise, the learner 'started to answer questions immediately' without looking through the whole text. When answering questions, he 'did not refer to the text and answered (incorrectly) all questions from memory'.

This observation was echoed by the learner's Grade 3 teacher:

...the learner struggled to read and understand at the same time ... he was good with oral activities but avoided writing and answering comprehension questions. [Teacher, female, Grade 3, 56]

This may look like the learner was impulsive. However, the researcher believed he possessed very few, if any, strategies such as making connections, predicting, questioning, monitoring, visualising and summarising to utilise when he encountered difficulty. In some instances, the learner 'became distracted' and lost interest in the comprehension exercise (Prado \& Plourde 2011).

When asked about the approach the Grade 3 teacher used when teaching comprehension, she said the following:

I don't tell them the exact strategy...I won't say "today we are learning about inferring information or similarities and differences." ...I don't use that terminology. [Teacher, female, Grade 3, 56] 
She added:

I will just guide and lead them through the activity... [Teacher, female, Grade 3, 56]

The explicit teaching of reading strategies required the researcher to model the strategy, allow for guided practice, and then the learner had an opportunity for individual application where he practised these strategies independently (Prado \& Plourde 2011). This method of teaching distinguished between what the learner could do by himself without help and what he could do with adult guidance.

During the observations, the researcher noted the following about the learner's response to the explicit teaching of the reading strategy 'monitoring':

He appeared unfamiliar with the concept...he seemed to lose interest when I started to model the strategy. [Researcher, female, Grade 4, 23]

In contrast to the observations made by the researcher, as well as the responses from the Grade 3 teacher, the post-test results indicated that explicit, small group instruction was of value to the learner and improved his reading comprehension ability.

In the interview, the teacher mentioned an important point that the CAPS document prescribes what skills the learner must acquire but does not prescribe how they must be taught.

The document just lists the types of questions ... the document doesn't tell you how to go about teaching it. [Teacher, female, Grade 3, 56]

Research surrounding the teaching of reading strategies has shown that teachers seldom spend time on the development and instruction of reading comprehension (Klapwijk 2012).

The interview with the Grade 3 teacher revealed that she integrated comprehension with language lessons:

I always integrate it (comprehension) into a whole language lesson ... comprehension is learnt on a daily basis not always in English, even in subjects like Maths ... [Teacher, female, Grade 3, 56]

Many teachers believe that teaching reading strategies is too time consuming and many feel inadequately trained to do so (Klapwijk 2012). As the process of explicit teaching can be time consuming on the teacher's part, many teachers elect the alternative method - implicit teaching. This choice results in comprehension being tested rather than taught (Oyetunji 2013). These points are confirmed by Spaull (2015) who state that in South Africa our schools are: '... characterised by wasted learning time, incomplete coverage of the curriculum, weak subject and content knowledge among teachers, low cognition demands placed on learners and exceedingly poor educational outcomes'.

\section{Recommendations}

While extracting explicitly stated information is a crucial skill, it is suggested that the focus of teaching reading comprehension be expanded to include deliberate instruction of higher order comprehension skills. The teaching of metacognition should be implemented from the start of a learner's school career enabling the learner to access and utilise this skill throughout the school career. Learners should work with informational texts early on in the Foundation Phase in an attempt to prevent comprehension challenges faced by learners in Grade 4 upwards.

Given the literacy and comprehension failures evident in South Africa, greater attention should be placed on reading comprehension in the language curriculum. The use of reading strategies coupled with explicit instruction has proven to be beneficial in improving comprehension ability. It is recommended that learning, teaching and support material be better developed to support the explicit teaching of many different reading strategies.

A further recommendation is that initial teacher education programmes offer training in the teaching of reading strategies, focusing on instructional practices, as a component of their language courses. This input was absent from the researcher's undergraduate training programme. The training of reading strategies should be offered to all phases; not only Foundation Phase teachers who traditionally set the groundwork for reading and reading comprehension.

\section{Conclusion}

The purpose of this interpretative case study was to ascertain what instructional reading strategies can improve comprehension skills. Two main conclusions can be drawn. Firstly, learners are generally well equipped to deal with questions which require retrieval of explicitly stated information but struggle with higher-order level questions such as drawing inferences or evaluating content. Learners need to be equipped to work with higher order questions from an early grade. Exposure alone is not adequate.

Secondly, it was established that certain instructional practices are more favourable than others when teaching reading strategies. Guided reading, in a small group context, was used as part of the strategy to explicitly teach reading comprehension strategies.

This interpretative case study focussed on the development of reading comprehension skills of one learner with a focus on making straightforward inferences and examining and evaluating content, language and textual elements. It cannot be assumed that the outcome will be the same for other learners. Further improvements may have been possible had the duration of the intervention programme been longer. Implications for further research using the same framework include interviewing specialists, such as Learning Support Teachers, Occupational Therapists or Educational 
Psychologists to gain a more in-depth view on reading comprehension.

The current approach to reading comprehension instruction is not producing the desired outcomes. Reading comprehension and the instruction thereof must be prioritised to include explicitly taught reading strategies from an early grade. Further research based on the role of reading strategies in the South Africa classroom, as well as pilot projects involving the use of a variety of instructional practices such as explicit reading strategy instruction, guided reading and small group instruction, may be beneficial to the development and improvement of the comprehension ability of South African learners. In order for this to happen, role-players in the education sector need a shift in perspective.

\section{Acknowledgements Competing interests}

The authors declare that they have no financial or personal relationships which may have inappropriately influenced them in writing this article.

\section{Authors' contributions}

S.B. was the original researcher. J.C. was the supervisor for this study and co-finalised the manuscript for publication with her.

\section{References}

Bruner, J., 1997, 'Celebrating divergence: Piaget and Vygotsky', Human Development 40(2), 63-73. https://doi.org/10.1159/000278705

Cambourne, B., 2004, 'Holistic, integrated approaches to reading and language arts instruction: The constructivist framework of an instructional theory', in A.E. Farstrup \& S.J. Samuels (eds.), What research has to say about reading instruction, pp. 5-47, 3rd ed., The International Reading Association, Newark, DE.

Cohen, R., 2008, Developing essential literacy skills: A continuum of lessons for Grades $K-3$, International Reading Association, Newark, DE.

Cohen, L., Manion, L. \& Morrison, K., 2007, Research methods in education, 6th edn., Routledge, London.

Combrinck, C., Van Staden, S. \& Roux, K., 2014, 'Developing early readers: Patterns in introducing critical reading skills and strategies to South African children', Reading and Writing 5(1), 1-9. https://doi.org/10.4102/rw.v5i1.45

Donald, D., Lazarus, S. \& Lolwana, P., 2007, Educational psychology in social context, 3rd edn., Oxford University Press, Cape Town.

Duke, N. \& Block, M.K., 2012, 'Improving reading in the primary grades', The Future of Children 22(2), 55-72. https://doi.org/10.1353/foc.2012.0017

Flynt, E.S. \& Cooter, R.B., 2005, 'Improving middle-grades reading in urban schools: the Memphis comprehension framework', The Reading Teacher 58(8), 774-780. https://doi.org/10.1598/RT.58.8.8

Geary, P., 2006, 'Every child a reader: A national imperative', Reading Improvement 43(4), 179-184.

Gower, P., 2008, 'All schools need decent funding', Mail \& Guardian, 9-15 May.

Henning, E., Van Rensburg, W. \& Smit, B., 2007, Finding your way in qualitative research, Van Schaik, Pretoria.
Horowitz, F.D., Darling-Hammond, L., Bransford, J., Comer, J., Rosebrock, K., Austin, K. et al., 2005, 'Educating teachers for developmentally appropriate practice', in L. Darling-Hammond \& J. Bransford (eds.), Preparing teachers for a changing world, parling-Hammond \& J. Bransford (eds.), Preparis, Jossey-Bass, San Francisco, CA
pp.

Howie, S., Van Staden, S., Tshele, M., Dowse, C. \& Zimmerman, L., 2012, Progress in International Reading Literacy Study 2011, South African children's reading literacy achievement: Summary Report, Centre for Evaluation and Assessment, University of Pretoria, Pretoria.

Klapwijk, N.M., 2012, 'Reading strategy instruction and teacher change: Implications for teacher training', South African Journal of Education 32, 191-204. https://doi. org/10.15700/saje.v32n2a618

Kumar, R., 2011, Research methodology: A step by step guide for beginners, Sage Publications, London

Leedy, P.D. \& Ormrod, J.E., 2005, Practical research: Planning and design, Pearson Education Inc., Upper Saddle River, NJ.

Lucy, J.A., 1988, 'The role of language in the development of representation: A comparison of Piaget and Vygotsky', Laboratory of Comparative Human Cognition 10(4), 99-103.

McLaughlin, M., 2006, Guided comprehension in the primary grades, International Reading Association, Newark, DE.

McNamra, D.S., Ozuru, Y. \& Floyd, R.G., 2011, 'Comprehension challenges in the fourth grade: The roles of text cohesion, text genre, and readers' prior knowledge', International Electronic Journal of Elementary Education 4(1), 229-257, viewed 15 March 2015, from http://129.219.222.66/pdf/13_IEJEE_4_1_McNamara_Ozuru Floyd.pdf

Merriam, S., 2009, Qualitative research: A guide to design and implementation, Jossey-Bass, San Francisco, CA.

Mokhtari, K. \& Reichard, C.A., 2002, 'Assessing students' metacognitive awareness of reading strategies', Journal of Educational Psychology 94(2), 249-259. https://doi. org/10.1037/0022-0663.94.2.249

Moss, B. \& Young, T.A., 2010, Creating life-long readers through independent reading, International Reading Association, Newark, DE.

Mullis, I.V.S., Martin, M.O., Kennedy, A.M., Trong, K.L. \& Sainsbury, M., 2009, PIRLS 2011 Assessment Framework, TIMSS and PIRLS International Study Centre, Boston College, Boston, MA.

National Department of Basic Education, 2011, National curriculum statement, curriculum and assessment policy statement: Intermediate phase Grade 4-6, Government Printers, Pretoria.

National Department of Basic Education, 2014, Report of the annual national assessment of 2014, Grades 1 to 6 \& 9, Government Printers, Pretoria.

Oyetunji, C., 2013, 'Does reading strategy instruction improve students' comprehension?' Journal for Language Learning 29(2), 33-55.

Patton, M.Q., 2002, Qualitative research and evaluation methods, 3rd edn., Sage Publications, Thousand Oaks, CA.

Prado, L. \& Plourde, L.A., 2011, 'Increasing reading comprehension through the explicit teaching of reading strategies: Is there a difference among the genders?' Reading Improvement 48(1), 32-43.

Sanacore, J. \& Palumbo, A., 2009, 'Understanding the fourth grade slump: Our point of view', The Educational Forum 73(1), 67-74. https://doi org/10.1080/00131720802539648

Santrock, J.W., 2011, Educational psychology, 5th edn., McGraw-Hill, New York.

Spaull, N., 2015, Schooling in South Africa: How low-quality education becomes a poverty trap, viewed 01 May 2017, from http://ci.org.za/depts/ci/pus/pdf/ general/gauge2015/Child_Gauge_2015-Schooling.pdf

Spaull, N., Van der Berg, S., Wills, G., Gustafsson, M. \& Kotzé, J., 2016, Foundations getting reading right, Final report to the Zenex Foundation on poor student performance literacy and numeracy, University of Stellenbosch, Stellenbosch.

Taylor, B.M., Pearson, D., Clark, K. \& Walpole, S., 2000, 'Effective schools and accomplished teachers: lessons about primary-grade reading instruction', The Elementary School Journal 101(2), 121-165. https://doi.org/10.1086/499662

Van Staden, S., 2012, PIRLS overall results [Power point presentation], Centre for Evaluation and Assessment, University of Pretoria, Pretoria.

Wertsch, J.V., 1990, 'The voice of rationality in a socio-cultural approach to mind', In L.C. Moll, (ed.). Vygotsky and education: Instructional implications and applications of socio-historical psychology, Cambridge University Press, New York.

Western Cape Education Department, 2015, WCED Systemic tests for Grades 3, 6 and 9: 2015 results, [Power point presentation] Research Department, Cape Town.

Wittmer, D.S., Petersen, S.H. \& Puckett, M.B., 2013, The young child: Development from pre-birth through age eight, Pearson, New York. 